EMPO-559

Rev. 2

\title{
OAK RIDGE Y-12 PLANT EMERGENCY ACTION LEVEL (EAL) PROCESS
}

\author{
E. G. Bailiff \\ J. D. Bolling
}

August 2000

Prepared by the

Emergency Management Program Organization Oak Ridge, Tennessee 37831-8133

Managed by

LOCKHEED MARTIN ENERGY SYSTEMS, INC.

for the

U.S. DEPARTMENT OF ENERGY

Under Contract No. DE-AC05-84OR21400 


\section{DISCLAIMER}

This report was prepared as an account of work sponsored by an agency of the United States Government. Neither the United States Government nor any agency thereof, nor any of their employees, makes any warranty, express or implied, or assumes any legal liability or responsibility for the accuracy, completeness, or usefulness of any information, apparatus, product, or process disclosed, or represents that its use would not infringe privately owned rights. Reference herein to any specific commercial product, process, or service by trade name, trademark, manufacturer, or otherwise, does not necessarily constitute or imply its endorsement, recommendation, or favoring by the United States Government or any agency thereof. The views and opinions of authors expressed herein do not necessarily state or reflect those of the United States Government or any agency thereof. 
EMPO-559

Rev. 2

\title{
OAK RIDGE Y-12 PLANT EMERGENCY ACTION LEVEL (EAL) PROCESS
}

August 2000

\author{
Prepared by the \\ Emergency Management Program Organization \\ Oak Ridge, Tennessee 37831-8133 \\ Managed by \\ LOCKHEED MARTIN ENERGY SYSTEMS, INC. \\ for the \\ U.S. DEPARTMENT OF ENERGY \\ Under Contract No. DE-AC05-84OR21400
}




\section{TABLE OF CONTENTS}

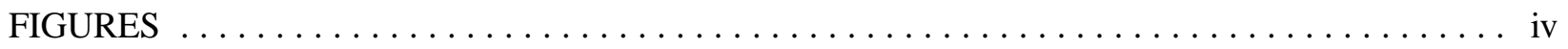

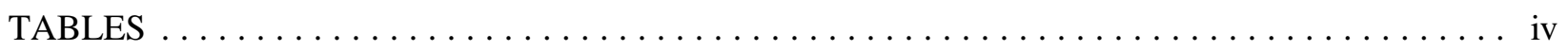

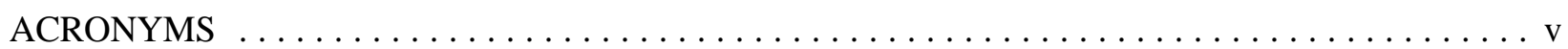

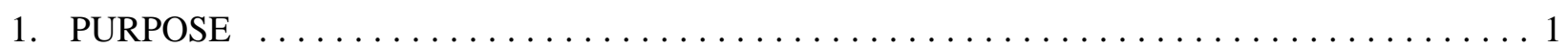

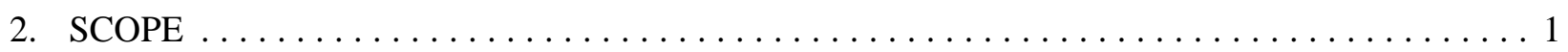

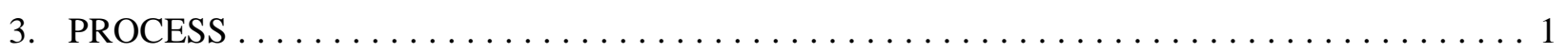

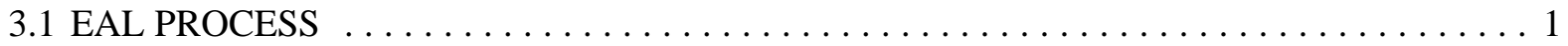

3.2 CATEGORIZATION/CLASSIFICATION SYSTEM FOR OPERATIONAL

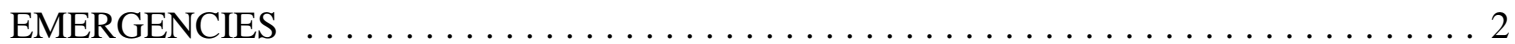

3.2.1 Event Classification and Protective Action Criteria $\ldots \ldots \ldots \ldots \ldots \ldots \ldots \ldots$

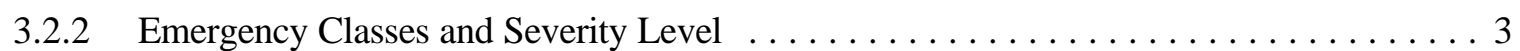

3.3 DEVELOPMENT OF EMERGENCY ACTION LEVELS (EALs) $\ldots \ldots \ldots \ldots \ldots \ldots \ldots \ldots$

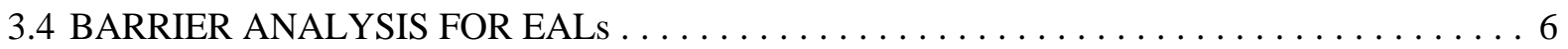

3.5 SYMPTOM-BASED AND EVENT-BASED EALs $\ldots \ldots \ldots \ldots \ldots \ldots \ldots \ldots \ldots$

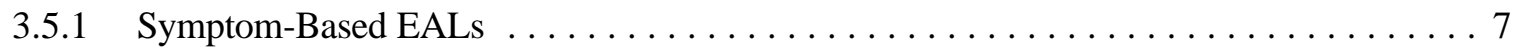

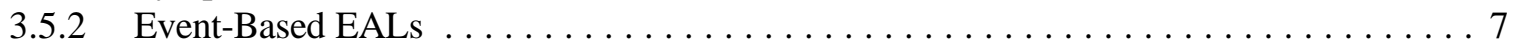

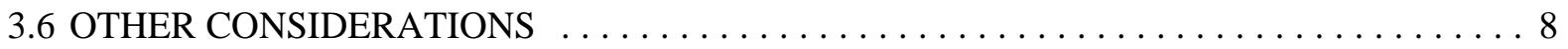

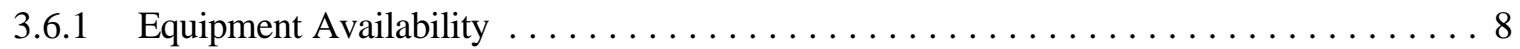

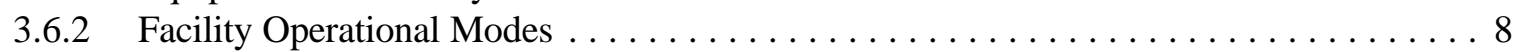

3.7 INTEGRATION OF EALs WITH NORMAL AND OFF-NORMAL OPERATIONS $\ldots \ldots \ldots 9$

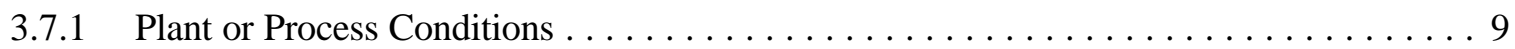

3.7.2 Hazardous Material Conditions . . . . . . . . . . . . . . . . . . . . 10

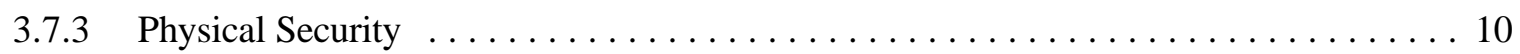

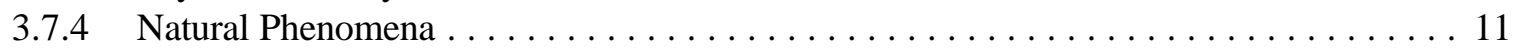

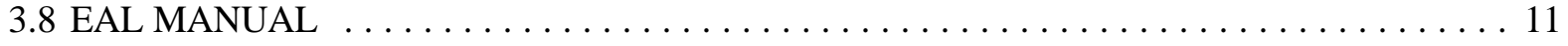

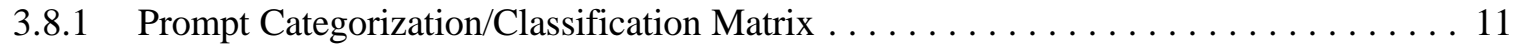

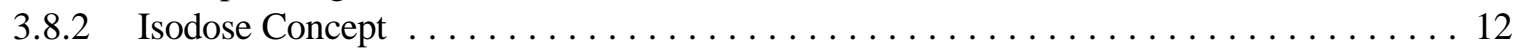

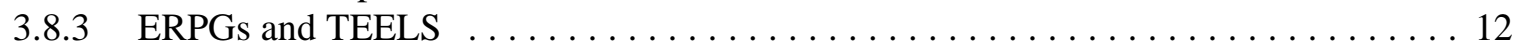

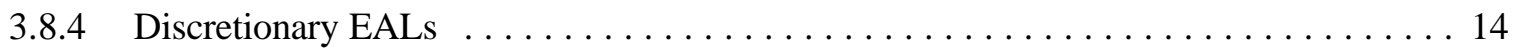

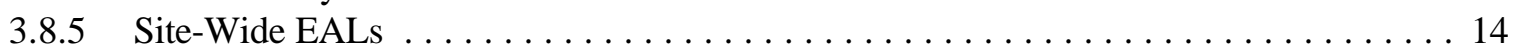

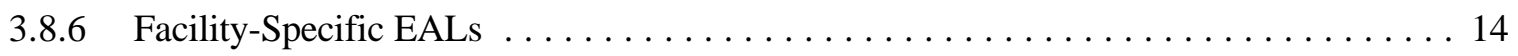

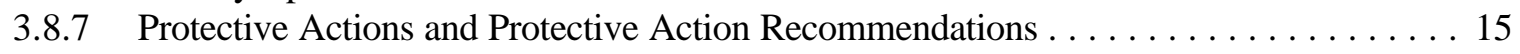

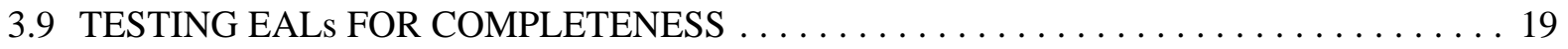

3.10 TRAINING AND IMPLEMENTATION OF EALs $\ldots \ldots \ldots \ldots \ldots \ldots \ldots \ldots \ldots \ldots \ldots$

3.11 EAL CONFIGURATION MANAGEMENT $\ldots \ldots \ldots \ldots \ldots \ldots \ldots \ldots \ldots \ldots \ldots \ldots \ldots$

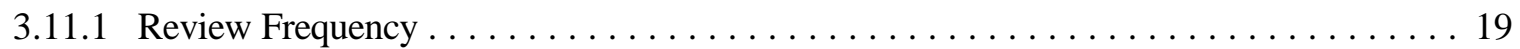

3.11 .2 Change Control . . . . . . . . . . . . . . . . . . . . . . . . . . . . . . . 19

3.11.3 Review and Approval of the Facility-Specific EALs . . . . . . . . . . . . . . . . 19

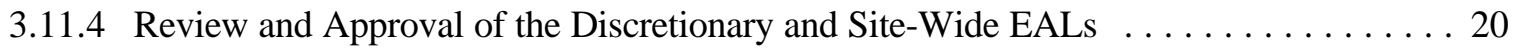

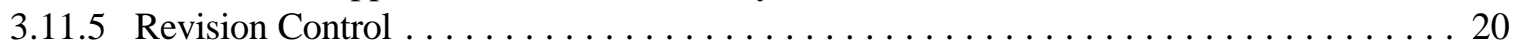

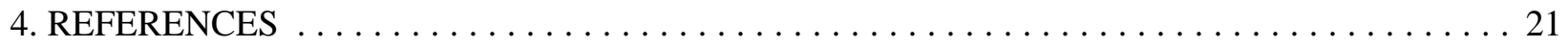




\section{APPENDIX CONTENTS}

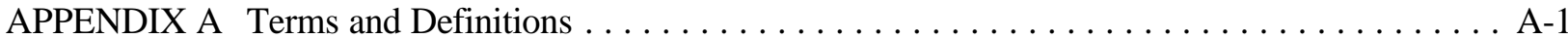

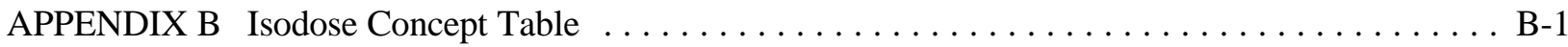

APPENDIX C Barrier Approach to Emergency Action Level Development . . . . . . . . . . . . C 


\section{FIGURES}

Fig. 1. Use of EALs to Categorize/Classify an Event $\ldots \ldots \ldots \ldots \ldots \ldots \ldots \ldots \ldots \ldots \ldots \ldots$

Fig. 2. ERPGs and TEELs used in emergency planning $\ldots \ldots \ldots \ldots \ldots \ldots \ldots \ldots \ldots \ldots \ldots \ldots \ldots$

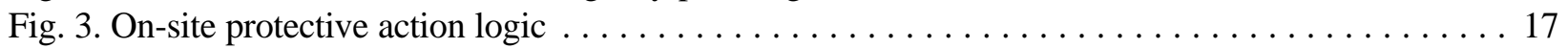

Fig. 4. Off-site protection action recommendation guide $\ldots \ldots \ldots \ldots \ldots \ldots \ldots \ldots \ldots \ldots$

\section{TABLES}

Table 1. Examples of event-based (subjective) and symptom-based (objective) EAL statements $\ldots \ldots 8$

Table 2. Example EALs for different severity levels of the same initiating condition $\ldots \ldots \ldots \ldots$ 


\section{ACRONYMS}

$\begin{array}{ll}\text { AIHA } & \text { American Industrial Hygiene Association } \\ \text { CEDE } & \text { Committed Effective Dose Equivalent } \\ \text { DOE } & \text { Department of Energy } \\ \text { EAL } & \text { Emergency Action Level } \\ \text { EMHA } & \text { Emergency Management Hazards Assessment } \\ \text { EMPO } & \text { Emergency Management Program Organization } \\ \text { EPIP } & \text { Emergency Plan Implementing Procedure } \\ \text { EPZ } & \text { Emergency Planning Zone } \\ \text { ERO } & \text { Emergency Response Organization } \\ \text { ERPG } & \text { Emergency Response Planning Guidelines } \\ \text { ESD } & \text { Emergency Services Department } \\ \text { GE } & \text { General Emergency } \\ \text { HEPA } & \text { high-efficiency particulate air } \\ \text { ORR } & \text { Oak Ridge Reservation } \\ \text { PAC } & \text { protective action criteria } \\ \text { PAR } & \text { Protective Action Recommendation } \\ \text { PEL } & \text { possible exposure limit } \\ \text { PSS } & \text { Plant Shift Superintendent } \\ \text { SAE } & \text { Site Area Emergency } \\ \text { SCAPA } & \text { Subcommittee on Consequence Assessment and Protective Action } \\ \text { TEDE } & \text { Total Effective Dose Equivalent } \\ \text { TEEL } & \text { Temporary Emergency Exposure Limits } \\ \text { TLV } & \text { threshold limit value } \\ \text { USQD } & \text { Unreviewed Safety Question Determination } \\ & \end{array}$




\section{PURPOSE}

This document establishes requirements and standard methods for the development and maintenance of the Emergency Action Level (EAL) Process used by all lead and event contractors for emergency planning and preparedness. The EAL process ensures a technically defensible approach to emergency categorization/classification in accordance with DOE Order 151.1.

\section{SCOPE}

The instructions provided in this document include methods and requirements for the development and approval of the EAL process. EALs are developed to cover events inside and outside the Y-12 Plant and to allow the Emergency Response Organization (ERO) to classify or reclassify events promptly based on specific indicators.

\section{PROCESS}

This document is divided into the following 11 subsections:

1. EAL Process,

2. Categorization/Classification System for Operational Emergencies,

3. Development of EALs,

4. Barrier Analysis for EALs,

5. Symptom-Based and Event-Based EALs,

6. Other Considerations,

7. Integration of EALs with Normal and Off-Normal Operations,

8. EAL Manual,

9. Testing EALs for Completeness,

10. Training and Implementation of EALs, and

11. Configuration Management.

\subsection{EAL PROCESS}

EALs can be written so as to classify an event based on the indicators contained within the EAL statement, or they can be written as triggers to obtain additional information quickly to properly classify an event. For example, in the case of severe weather causing substantial damage to a facility containing hazardous material, the confirmation of the event itself could lead to an event classification determination. For releases of hazardous material, EALs - which are based on a conservative meteorological set (i.e., wind speed $1 \mathrm{~m} / \mathrm{s}$, atmospheric stability F) - may be a trigger to determine real-time downwind consequences based on actual or default source terms. The result of the consequence assessment would then drive the event classification.

A default listing of source terms (radiological and direct release chemical) and/or material at risk (for chemical spills with and without containment) may be provided within the facility-specific EALs. This listing allows for real-time consequence assessment to aid in the determination of the appropriate emergency classification. This default listing can be either a separate Appendix or included within the EAL statement.

EALs form the link between the severity of an emergency, as reflected in the event classification system, and the facility-specific indicators of the event. For any given type of event, use one or more observable condition(s) 
individually or in combination as criteria for the event. The criteria relate (1) to an actual release of hazardous materials, or (2) to conditions that represent various levels of degradation or loss of ability to control those materials.

Operational emergencies may be further classified in order of severity (least to more severe), as follows:

- Alert

- Site Area Emergency

- General Emergency

The purpose of differentiating these classes by severity is for implementing specific emergency actions, including those required response activities and notifications commensurate with the degree of hazard presented by the event.

All Y-12 Plant facilities must assess their operations and activities to determine the potential for events involving hazardous materials; weapons, components, or test devices; safeguards and security; and on-site transportation accidents involving hazardous material under DOE control to create an operational emergency.

\subsection{CATEGORIZATION/CLASSIFICATION SYSTEM FOR OPERATIONAL EMERGENCIES}

Event categorization/classification ensures the assignment of a level of severity to a particular condition or event as determined by specific indicators and allows a correlation with protective action criteria (PAC).

Operational emergencies are categorized according to the following types:

- health and safety,

- environmental,

- security and safeguards,

- off-site DOE transportation, and

- hazardous material

An operational emergency is a significant event or condition that requires time-urgent response from outside the facility. Operational emergencies involving a hazardous material release that is greater than the PAC [radiological, 1-rem Total Effective Dose Equivalent (TEDE), or nonradiological Emergency Response Planning Guidelines (ERPG)-2 or equivalent], $30 \mathrm{~m}$ or greater from the point of release, are classified as one of the following emergency classes:

- Alert

- Site Area Emergency

- General Emergency

The process of categorizing events as operational emergencies and classifying significant hazardous material events was created to ensure rapid recognition of emergency conditions and timely response. 


\subsubsection{Event Classification and Protective Action Criteria}

1. Actual or potential consequence from a release of hazardous material resulting in a dose or exposure that equals or exceeds PAC at (1) $30 \mathrm{~m}$ from the release, (2) the facility boundary, or (3) the site boundary defines the emergency class. Appendix B, "Isodose Concept," provides a graphic depiction of the Isodose Concept applied to event classification and PAC.

2. EALs are developed by using the results of the facility Emergency Management Hazards Assessment (EMHA) process to identify specific event indicators (e.g., alarms, monitors, samples, observations) corresponding to actual or potential accident consequences that equal or exceed a PAC at $30 \mathrm{~m}$, facility boundary or site boundary.

A simplified overview on the use of EALs to categorize/classify an event is provided in Figure 1.

\subsubsection{Emergency Classes and Severity Level}

\subsubsection{Alert}

Health and safety impacts for an Alert emergency classification are expected to be confined within the incident facility boundary.

The Alert class is appropriate if hazardous material exposures $\geq \mathrm{PAC}$ [1 rem TEDE or ERPG-2/equivalent Temporary Emergency Exposure Limits (TEEL)] can occur only within a facility boundary.

An Alert has occurred if an unplanned event results in hazardous material being released to the environment in concentrations that result in exposures $\geq \mathrm{PACs}$ at $30 \mathrm{~m}$ from the point of release (point sources) or the edge of the spill area (area sources) and is less than a PAC at the facility boundary, or represents a fraction of PAC at or beyond the facility or exclusion boundary.

An Alert classification represents events in progress or having occurred that involves an actual or potential substantial degradation in the level of safety or security of a nuclear weapon, component, or test device that would not pose an immediate threat to workers or the public or that could, with further degradation, produce a Site Area Emergency (SAE) or General Emergency (GE).

\subsubsection{Site Area Emergency}

An SAE is an event or condition expected to have significant on-site impacts beyond the facility boundary of the incident facility. Protective actions for on-site personnel and full mobilization of on-site resources may be needed to deal with the event and its consequences.

The intention of declaring an SAE is to provide for initiation of predetermined protective actions for on-site personnel, as well as notification and assembly of emergency response personnel and equipment.

For accidents or incidents occurring at Y-12 facilities, the SAE class is appropriate if hazardous material exposures $\geq$ PAC can be expected at or beyond the facility boundary but $\angle \mathrm{PAC}$ at the site boundary.

An SAE classification is declared whenever an actual or potential threat to the integrity of a nuclear weapon component or test device that may adversely impact the health and safety of on-site personnel or that could, with further degradation, produce a GE. 
Fig. 1. Use of EALs to Categorize/Classify an Event. (figure 1 follows this page) 


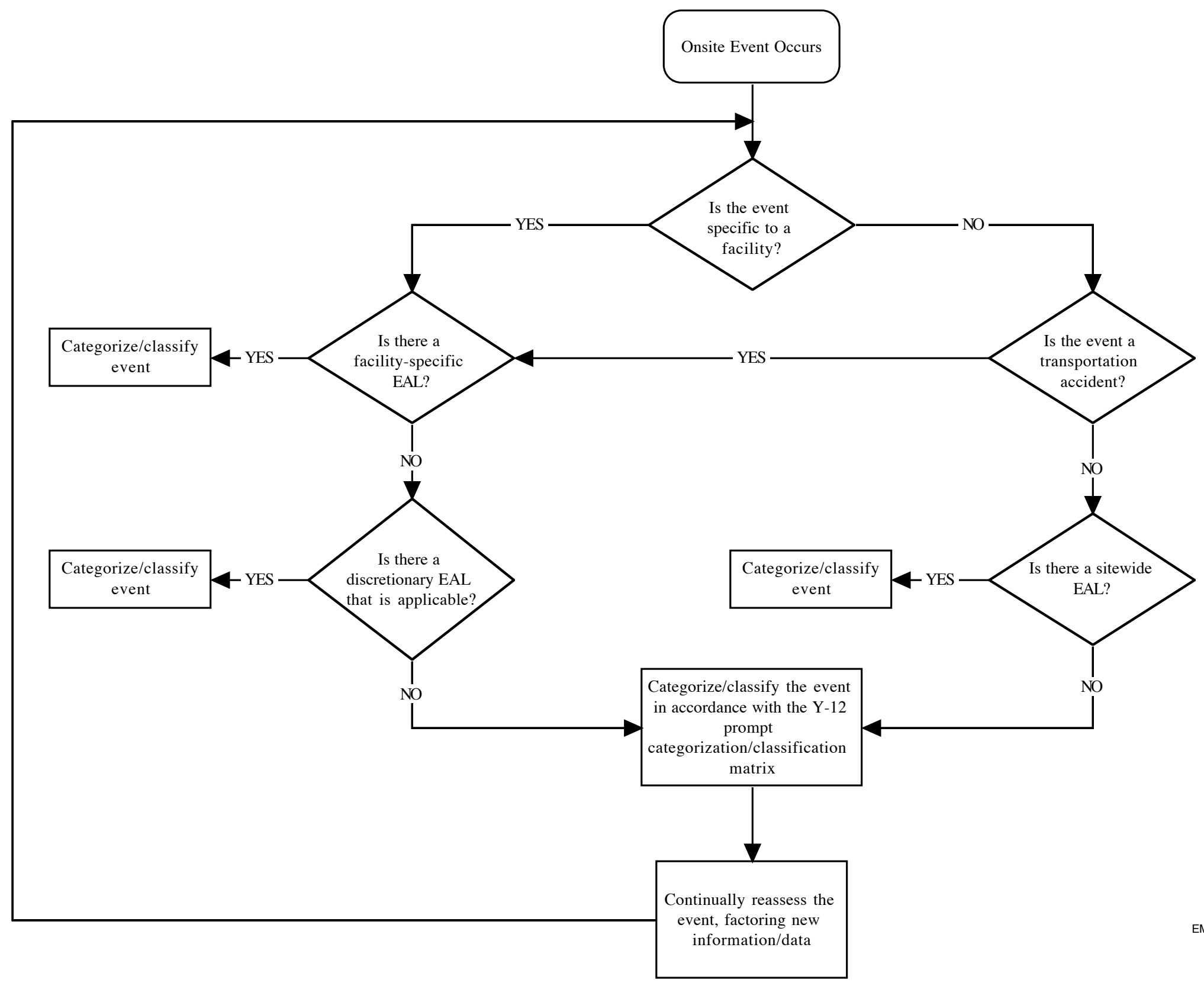

EM-F146 


\subsubsection{General Emergency}

Events or conditions expected to produce consequences that require protective actions for the general public fall within the GE classification. Such conditions require full mobilization of all available DOE and off-site resources to deal with the event and its consequences.

If hazardous material exposures $\geq \mathrm{PAC}$ can be expected at or beyond the site boundary, the GE class is appropriate for accidents or incidents occurring at Y-12 facilities

A GE is declared whenever actual or likely catastrophic failures in safety or security systems threaten the integrity of a nuclear weapon component or test device that may adversely impact the health and safety of workers and the public.

\subsection{DEVELOPMENT OF EMERGENCY ACTION LEVELS (EALs)}

EMHA process constitutes the technical basis for the emergency management program. EMHA identifies and characterizes the hazards associated with a facility, determines the events and conditions that could lead to releases, and quantifies the potential on-site and off-site consequences of each postulated accident.

Facility-specific means/indicators to recognize an event(s) as an Operational Emergency not involving significant releases of hazardous materials are developed for the spectrum of emergency conditions identified in the Hazards Survey with the potential to be Operational Emergencies. Also, facility-specific EALs are developed for the spectrum of potential Operational Emergencies involving significant releases of hazardous materials identified by a hazards assessment.

Among the supporting materials to be developed for each identified accident scenario are the corresponding initiating conditions, accident mechanisms, equipment or system failures, event indicators, and contributing events. This information is used to identify the specific equipment or other observable methods of detection and recognition for each accident scenario and is incorporated into the EAL matrix when applicable/available. The information should include instrument readings, equipment status indicators, measurable off-site/on-site parameters, discrete observable events, results of analyses, or another observed phenomenon.

To the maximum extent possible, the indications selected for use are to be directly observable, unambiguous, and objective.

The results of EMHA provide a quantitative estimate of the consequences of each release at specific receptor locations as specified in the Emergency Management Hazards Assessment Process, EMPO-558. EMHA analyses of atmospheric releases are based on two sets of dispersion conditions.

The first case will represent a "conservative" estimate of consequences. For atmospheric release of hazardous materials, a wind speed of $1 \mathrm{~m} / \mathrm{s}$ with stability class of $F$ and a ground level release is utilized, with the exception of spills and subsequent evaporation of hazardous materials. For spill scenarios, a more conservative approach, as indicated by consequence results from modeling, will utilize a typical meteorological set of D stability and a wind speed of $3 \mathrm{~m} / \mathrm{s}$. Consequences calculated using these conditions will be used to develop EALs and to determine the size of emergency planning zone (EPZ). In addition, wind direction is not utilized in developing EALs or emergency planning zones (EPZs); rather, the closest distance to a receptor (e.g., facility or site boundary) will be the determining factor. 
The second case will approximate a "typical" set of conditions, as identified above for a spill scenario, D stability and $3 \mathrm{~m} / \mathrm{s}$ wind speed. Consequences calculated using these conditions are for general reference and response planning purposes, which are useful in offsite planning with local authorities and as a resource for emergency response personnel.

For detection and recognition methods that yield a correlation to actual or potential consequence, it is possible to calculate values or conditions that indicate when an emergency class may have been reached. Examples of indications or conditions for which values are calculated are installed alarms, direct instrument readings, and indicated status of systems or equipment.

Using PAC as the threshold value, calculate values for installed instruments, sample results, and system status that indicate when the threshold value is reached at the designated receptor locations. These values become the EAL triggers for determining the potential emergency class.

For example, in an accident resulting in a release of radioactive material through the stack exceeding the criteria for GE, with one means of detection being the stack monitor, calculate instrument readings marking the onset of Alert, SAE, and GE and identify as EAL trigger values. Reaching the applicable trigger value drives the facility to obtain real-time consequence assessment results from other systems and/or instrumentation to confirm the appropriate emergency class.

Some accident indicators of symptoms are not detectable by quantifiable methods or may be indirectly recognized.

If a readily recognizable event (i.e., fire) has the potential for causing a release of hazardous material and an actual release would be difficult or impossible to confirm (i.e., no quantifiable detection method), then the recognition of the event becomes the EAL trigger. Base the event classification on the maximum consequences determined in the EMHA, with the stipulation that the event can be modeled using the "maximum source term" in the EMHA under the conservative meteorological set.

In many cases involving the actual or potential release of hazardous material, there will be either minimal or no installed instrumentation designed to detect a release. State these EALs in terms of the observable indicators or conditions. Base the resulting event classification on the consequence resulting from the discharge of the total quantity of material.

\subsection{BARRIER ANALYSIS FOR EALS}

The barrier analysis technique examines the potential for release of hazardous material in terms of the failure or degree of challenge to the barrier between the material and the environment. Besides identifying the basic information on which specific EALs are based, this technique provides a method of approaching the development of an integrated EAL scheme.

The physical and, possibly, administrative controls associated with safe facility operation are viewed as barriers, and the facility-specific EAL system is designed to determine the status of these barriers. The specific EALs developed to indicate degree of barrier challenge or failure are either symptom-based or event-based in nature.

Appendix C, "Barrier Approach to EAL Development," provides more information and examples on the application of this approach. 


\subsection{SYMPTOM-BASED AND EVENT-BASED EALs}

EALs may be either symptom-based or event-based. The distinction arises from the available methods of detecting and recognizing the event-initiating conditions.

\subsubsection{Symptom-Based EALs}

Symptom-based EALs are dependent on one or more observable conditions or parameter values (i.e., symptoms) that are measurable. They are often the same indicators used by operations personnel to monitor routine facility operation and include the following:

- recognize when these indicators begin to show off-normal readings,

- identify the probable causes,

- recognize the potential consequences, and

- take corrective actions.

The failure of or challenge to the facility's hazardous materials confinement barriers is directly related to the level of severity indicated by these symptoms.

The resulting EALs consist of specific quantified values (e.g., alarms, control instrument readings) which require no additional interpretation by the user. Determine the correct potential emergency class by comparing the observed value to EALs.

\subsubsection{Event-Based EALs}

Event-based EALs address the occurrence of discrete events with potential safety significance. Determine the level of severity by the degree to which hazardous material confinement barriers are failed or challenged as a result of the event.

Methods available to detect and quantify event-initiating conditions are often limited. State the resulting EALs in terms of the overall event descriptor and require a separate definition of what constitutes the event. For example, the recognition that an event has occurred may in itself become an EAL.

Event classification requires the interpretation of one or more qualitative conditions or discrete observable indicators to determine if the existing situation matches the descriptions contained in the event classification procedure.

The development of symptom-based EALs is the preferred approach, recognizing that usually there will be some initiating conditions that require an event-based approach.

Subjective (event-based) EALs can often be restated in more quantitative or objective (symptom-based) terms. Table 1 illustrates the difference between a subjective (event-based) EAL statement that requires much interpretation by the user and an objective (symptom-based) EAL statement for the same condition. Table 2 illustrates EALs for increasing severity levels for the same initiating condition. 
Table 1. Examples of event-based (subjective) and symptom-based (objective) EAL statements

\begin{tabular}{|c|l|l|}
\hline Initiating condition & \multicolumn{1}{|c|}{$\begin{array}{c}\text { Event-based (subjective) EAL } \\
\text { statement }\end{array}$} & \multicolumn{1}{|c|}{ Symptom-based (objective) EAL statement } \\
\hline Fire & $\begin{array}{l}\text { Fire in the chemical makeup room } \\
\text { of the ABC facility beyond the } \\
\text { incipient stage }\end{array}$ & $\begin{array}{l}\text { Fire in ABC facility as indicated by: } \\
\text { - Fire Alarm Enunciator for Zone 1, 3, or 6, } \\
\text { - and - }\end{array}$ \\
\hline Radiological release & $\begin{array}{l}\text { Breach of the XYZ HEPA filter } \\
\text { bank resulting in a radiological } \\
\text { stack release from ABC facility } \\
\text { corresponding to off-site dose of 1 } \\
\text { rem }\end{array}$ & $\begin{array}{l}\text { Confirmed ABC stack alpha monitor reading } \\
>3 \mathrm{E} 8 \mathrm{MCi} / \mathrm{s}\end{array}$ \\
\hline
\end{tabular}

Table 2. Example EALs for different severity levels of the same initiating condition

\begin{tabular}{|c|c|c|c|}
\hline $\begin{array}{l}\text { Initiating } \\
\text { condition }\end{array}$ & Alert & Site Area Emergency & General Emergency \\
\hline Fire & $\begin{array}{l}\text { Any fire in zones } 1 \text {, } \\
3 \text {, or } 4 \text { beyond the } \\
\text { incipient stage }\end{array}$ & $\begin{array}{l}\text { Fire causing radiological } \\
\text { release as indicated by: } \\
\text { - Fire alarm on Zone } 1 \text {, } \\
3 \text {, or } 4 \\
\text { - and - } \\
\text { - Stack monitoring } \\
\text { reading }>3 \mathrm{E}-2 \mu \mathrm{Ci} / \mathrm{s}\end{array}$ & $\begin{array}{l}\begin{array}{l}\text { Fire damages Vent Zone A filters as } \\
\text { indicated by: }\end{array} \\
\text { - } \\
\text { Alarm on filter temperature } \\
\text { sensor T-120 } \\
\quad \text { - and - } \\
\text { - Filter deluge activated as } \\
\text { indicated by flow sensor F-629 } \\
\quad \text { - and - } \\
\text { - Stack monitor reading off-scale } \\
\text { high }(>3 \mathrm{E} 3 \mu \mathrm{Ci} / \mathrm{s}) .\end{array}$ \\
\hline $\begin{array}{l}\text { Radiological } \\
\text { release }\end{array}$ & $\begin{array}{l}\text { Stack monitor } \\
\text { reading }>1 \mathrm{E}-3 \mu \mathrm{Ci} / \mathrm{s}\end{array}$ & $\begin{array}{l}\text { Stack monitor reading } \\
>3 \mathrm{E}-2 \mu \mathrm{Ci} / \mathrm{s}\end{array}$ & $\begin{array}{l}\text { Stack monitor reading off-scale high } \\
(>3 \mathrm{E} 3 \mu \mathrm{Ci} / \mathrm{s}) \text {. }\end{array}$ \\
\hline
\end{tabular}

\subsection{OTHER CONSIDERATIONS}

\subsubsection{Equipment Availability}

When matching initiating events to facility equipment to provide a means of detecting the event, recognize that under some accident conditions, the equipment may be nonoperational (e.g., loss of power) or be outside its operating limits (e.g., out of range).

\subsubsection{Facility Operational Modes}

Consider the conditions that exist during different operational modes when developing facility-specific EALs. 
During one mode of operation, an instrument reading of a specific value provides a clear indication of an accident condition, while in another mode it may not. An instrument used to detect an accident indicator during normal operations may not be available during standby mode.

For example, during routine operations in a facility, a reading exceeding $10 \mathrm{mrem} / \mathrm{h}$ on a specific area radiation monitor is a clear indication of an Alert level event; however, during maintenance with shielding removed, exceeding this value on the same monitor is normal.

Avoid setting an EAL that can be exceeded when no emergency exists. This caution will prevent event classification personnel from being put in a position of having to declare an emergency when one does not exist.

\subsection{INTEGRATION OF EALs WITH NORMAL AND OFF-NORMAL OPERATIONS}

During the facility EMHA process, various limits to operation of the facility may be included to reduce the hazard (e.g., quantity limits) or provide barriers to the hazard (e.g., administrative controls). Include these limits and controls in the appropriate facility operating procedures before the EALs are approved.

Many different indicators and symptoms may be monitored or observed to determine if facility conditions are normal or off-normal. The observation of these indicators and the recognition of their significance to the state of the facility is generally a routine function of operations.

Transition to emergency operations depends on the detection and recognition of specific accident event indicators and symptoms. This process is viewed as a natural extension to the routine monitoring used to determine facility status.

To the extent possible, integrate the methods employed for detection and recognition of accident events to make the transition from routine operations to emergency response.

A rigorous integration of EALs and event classification into existing site or facility procedures is not necessary and could lead to difficulty in maintaining the procedures. Conversely, keeping EALs totally separate and relying solely on memory and training during periods of high stress is insufficient. Use visual cues and other indicators in site or facility procedures to signal users to consult the event classification procedure.

The basis for classifying accident events is grouped into four general areas: Plant or Process Conditions, Hazardous Materials Conditions, Natural Phenomena, and Physical Security.

The following sections include some accident symptoms and indicators, potential methods of detection, and methods for incorporating the recognition of event classification into normal operations.

\subsubsection{Plant or Process Conditions}

This grouping is applicable to facilities containing more complex processes, such as processing facilities. Potential symptoms or indications that could identify the onset of an accident condition include abnormal indications for temperatures, pressures, fluid levels, flow rates, power loss, radiation levels, and fire detection. 
Detection methods include

- installed instrumentation and hardware, such as control room alarms/annunciator, local alarms, or indicators intended to detect changes in temperature, pressure, flow rate, fluid level, power, radiological conditions, chemical concentrations;

- sampling or measurement results;

- operator observation during inspection or walk-down; and

- employee observation during normal work activities.

\subsubsection{Hazardous Material Conditions}

This grouping covers the risk of release of hazardous materials from transportation accidents, burial grounds, process facilities, tank farms, storage tanks, transfer lines, etc. Within this grouping, potential symptoms and indicators that could identify the onset of an accident condition include

- excessive contamination levels,

- elevated dose rates,

- spills of hazardous material,

- unmonitored releases of hazardous material, and

- effluents containing excessive levels of hazardous materials.

Methods for detecting these symptom and indicators include

- operator observation during inspections or walk-downs,

- alarms and monitors,

- sampling or measurements, and

- employee or public report.

\subsubsection{Physical Security}

This group is composed of all security-driven events that could result in the release of or loss of control of hazardous materials. Potential symptoms and indications that could identify an actual or potential threat to the containment, control, or safeguarding of hazardous material include

- acts of sabotage,

- terrorist threat or attack,

- intrusion,

- theft,

- bomb threat or explosion,

- breach of security barrier, and

- loss of facility or site control.

Methods for detecting the symptoms and indicators of security-driven events include

- security alarm systems,

- security force observations,

- employee observations or public report, and

- intelligence agencies, local police, or other agency methods. 


\subsubsection{Natural Phenomena}

This group covers the emergency conditions occurring as a result of acts of nature. Symptoms and indications that could identify an actual or potential threat to the containment and control of hazardous material resulting from a natural phenomenon include

- observed tornado,

- high winds,

- high or low water levels,

- forest fire,

- earthquake, and

- lightning.

Methods for detecting the symptoms and indicators of events caused by natural phenomena include

- meteorological instrumentation,

- weather forecasts,

- water level sensors,

- employee or public observation, and

- news media report (e.g., tornado sighting, local flooding, etc.) (event should not be classified based on report, but should initiate investigation that could result in classification).

The elements required to ensure the proper sequence of actions leading to event classification include

- means of detecting symptoms or indications,

- recognition of significance of indications, and

- proper response to recognition (i.e., communication with classification authority).

Within the Y-12 Site's operating structure, many varied detection methods exist. The recognition of the significance of what is detected depends on training, the existence of "attention-getting" devices, and procedural links.

Transmittal of information to a person with authority to perform event classification [i.e., Y-12 Plant Shift Superintendent (PSS)] depends on the establishment of clear reporting relationships.

\subsection{EAL MANUAL}

A manual entitled "Oak Ridge Y-12 Plant Emergency Action Levels" will be maintained by the Y-12 Emergency Management Program Organization (EMPO) to include all relevant information used to categorize and classify emergency events in all facilities located at Y-12.

EALs will be numbered sequentially, as identified by EMPO.

The EAL manual will include the information summarized in the subsections listed under this section. 


\subsubsection{Prompt Categorization/Classification Matrix}

To offset deficiencies in EALs or unforeseen conditions, such as multiple events or loss of essential instrumentation during an accident, the Y-12 EAL process contains a "Prompt Categorization/Classification Matrix" containing the fundamental definitions of emergency classes that an individual responsible for classification can utilize to compare his/her subjective evaluation and make an emergency declaration.

\subsubsection{Isodose Concept}

The relationship between receptor points and emergency classification is commonly referred to as the "Isodose Concept." A graphic representation of this relationship, included in the EAL Manual for quick reference, is based on the following:

1. Thirty meters from the release point or edge of the spill. The consequence (e.g., radiation dose or peak concentration of a toxic chemical) at this receptor location provides the demarcation between an accident that would require emergency response organization involvement (e.g., Alert) and one that would not.

2. Distance from the release point or edge of the spill to the nearest facility boundary. The facility boundary is the demarcation between the facility and its immediate vicinity and the remainder of the site. The consequence (e.g., radiation dose or peak concentration of a toxic chemical) at this receptor location provides the demarcation between an Alert and SAE declaration.

3. Distance from the release point or edge of the spill to the closest site boundary. The consequence (e.g., radiation dose or peak concentration of a toxic chemical) at this receptor location is the demarcation for a GE declaration.

\subsubsection{ERPGs and TEELs}

The EAL manual will contain a list of community exposure limits used in emergency planning and response.

ERPGs are the most widely used and accepted community exposure limits at this time. ERPGs are developed through a peer-review process established by the American Industrial Hygiene Association (AIHA), and this review process has been validated by outside scientific agencies.

Unfortunately, many emergency planners have to perform hazard and consequence assessments for chemicals without ERPGs. For considering these chemicals in emergency planning at its sites, the Department of Energy (DOE) Emergency Management Advisory Committee's Subcommittee on Consequence Assessment and Protective Action (SCAPA) has developed TEELs. SCAPA was established to assist DOE's Director of Emergency Management by providing technical recommendations (radiological and nonradiological) in areas related to the health and safety of workers and the public.

SCAPA recognizes the validity (and preferability) of peer-reviewed ERPG values, and TEELs are only used when ERPGs do not exist. Simply put, TEELs represent a linear regression best-fit hierarchy of alternatives to ERPGs. The TEEL hierarchy uses occupational exposure limits [permissible exposure limit (PELs), threshold limit value (TLVs), etc.], and toxicity-based data to derive TEELs. The relationship of ERPGs and TEELs to emergency planning is shown in Figure 2. 
Fig. 2. ERPGs and TEELs used in Emergency Planning (figure 2 follows this page) 


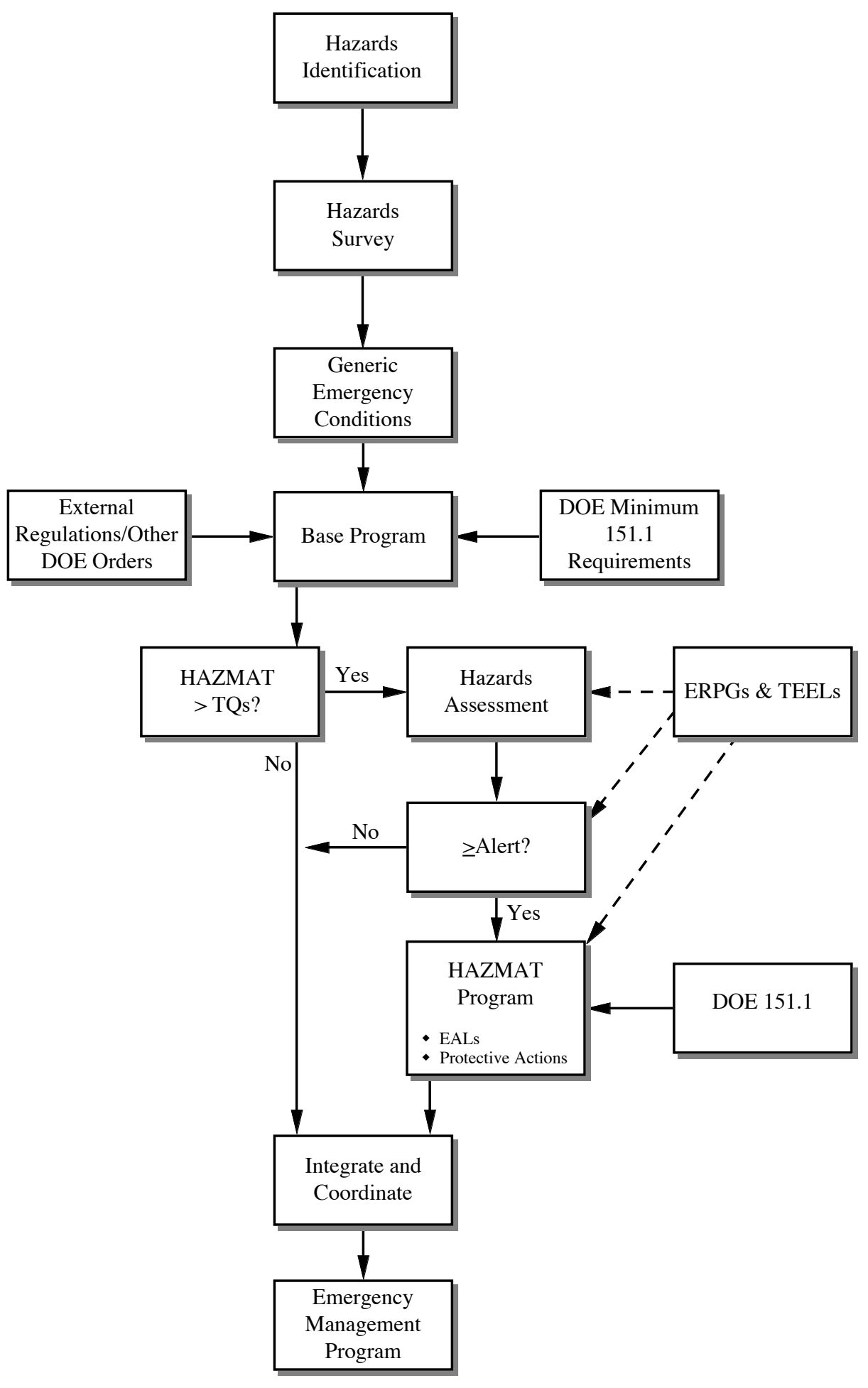


Whenever an ERPG is developed for a new chemical, ERPG replaces TEEL in emergency planning for that chemical because TEELs are subordinate to ERPGs. TEELs allow emergency planners to perform consequence assessments for chemicals for which there may never be ERPGs (i.e., for chemicals that may not be in wide enough use to be reviewed by the AIHA Emergency Response Planning Committee).

\subsubsection{Discretionary EALs}

To compensate for possible incompleteness in a facility-specific EMHA and/or EAL set, there are criteria by which personnel responsible for event classification (i.e., PSS or Emergency Director) can declare the level of emergency that most closely corresponds to the apparent conditions that exist at the time. Therefore, "discretionary" EALs are provided to cover situations not specifically covered in facility-specific EALs and should be used to classify events.

\subsubsection{Site-Wide EALs}

Most events will be classified on the basis of facility- or activity-specific symptoms or event indicators; however, some initiating conditions are a result of factors external to the facility. Some of these may not be identified through a facility-specific EMHA. The following are examples of conditions that do not originate in a specific facility and are likely to be classified only by a site-wide authority:

- Incidents affecting multiple operating areas or facilities.

- Heightened readiness required to deal with a range of possible challenges to security or safety at hazardous materials facilities.

- Classification based on impacts that are measured or calculated by a site-wide response organization.

- Transportation accidents involving facility-generated hazardous materials that occur onsite, but away from the facility.

The following are examples of initiating conditions indicative of the events previously listed:

- Earthquakes, tornado, blizzard/ice storm, and flooding.

- Train, plane, or land vehicle accidents involving either the onsite movement of or impact to hazardous materials.

- Release of hazardous material at an adjacent facility when such releases impact the capability of other site facilities to maintain control of hazardous materials.

- Security and safeguards events potentially affecting one or more site hazardous materials facilities.

\subsubsection{Facility-Specific EALs}

The EAL manual will contain facility-specific EALs resulting from the completion of the EMHA process as defined in EMPO-558, "Y-12 Emergency Management Hazards Assessment (EMHA) Process".

The EMHA prepared and maintained for a facility constitutes the technical basis for that facility's hazardous material emergency management program. The EMHA identifies and characterizes the hazards associated with a facility, determines the events and conditions that could lead to releases, and quantifies the potential onsite and offsite consequences of each postulated accident or emergency event or condition. The two steps within the EMHA process that provide the foundation on which to develop EALs and the corresponding event classifications are the development of accident and emergency event scenarios and the determination of the consequences. 
Among the supporting material to be developed for each identified accident or emergency event scenario are the corresponding initiating conditions, accidents mechanisms, equipment or system failures, event indicators, and contributing events. This information is to identify the specific observable methods of detection and recognition for each accident or emergency event scenario. The information could include an instrument reading, an equipment status indicator, a measurable offsite or onsite parameter, a discrete observable event, results of analyses, or another observed phenomenon. To the maximum extent possible, the indications selected for use should be directly observable, unambiguous, and objective.

The EMHA results provide a quantitative estimate of the consequences of each release at specific locations in terms of radiation dose or peak concentration of toxic chemicals. Another result of interest for EAL development is the maximum distance at which a PAC could be exceeded for each release. This information determines the emergency class associated with the release.

For detection and recognition methods that correlate directly with actual or potential consequences, it is possible to calculate specific values or conditions that correspond to each emergency class. Examples of indications for which specific values or conditions may be calculated are alarms, instrument readings, sample analysis results, and system or equipment status indicators (e.g., valve open vs. valve not open, system operable vs. system not operable). Specific values or conditions for instrument readings, sample analysis results, equipment status, etc., can be calculated that indicate when a PAC has been reached at a receptor of interest (e.g., facility or site boundary). These specific values or conditions become the EALs for determining the correct emergency class.

In some situations, accident or emergency event indicators or symptoms may not be detectable by quantitative methods, or they may be indirectly recognized. If a readily recognizable (observable) event (i.e., tank failure) has the potential for causing a release of hazardous material and an actual release would be difficult or impossible to confirm (i.e., no quantitative detection method), then the recognition or observation of the event becomes the EAL, and the event classification is based on the maximum consequence determined in the EMHA.

\subsubsection{Protective Actions and Protective Action Recommendations}

EALs will contain information relative to initial protective actions. Recommendations and guidance on planning for protective actions include the following principles:

- Serious early health effects should be avoided by taking protective actions to limit individual doses or exposures to levels below the threshold for those effects;

- The risk to individuals should be limited by taking protective actions which produce a positive net benefit to the individuals involved, that is, the risk to the individual from taking the protective action is lower than the risk from exposure or dose that is thereby avoided; and

- The overall risk to workers and the public should be limited, to the extent practicable, by reducing the population or collective dose (or exposure). Dose to emergency workers is as important as dose to the general public in adhering to this principle.

Two factors are critical in protecting employees and the public from a hazardous material release. First, effective protective actions must be based on accident conditions. Second, the risks of implementing protective actions should be compared against other options. Figure 3 illustrates the logic for initiating onsite protective actions, and Figure 4 depicts an offsite protective action recommendations logic. 
Y-12 EALs will typically contain information on the initial isolation zone, onsite protective actions, and offsite protective action recommendations.

Initial Isolation Zone. Based on information from the North American Emergency Response Guidebook, distances will be defined that identify to first responders the radius that dangerous and life-threatening concentrations of material may exist. These distances reflect the area likely to be affected during the first 30 minutes following a hazards materials release and could increase with time.

Onsite Protective Actions. Several protective actions can be implemented individually or in combination to protect onsite workers. The EAL will contain information on actions that will provide increased worker protection following a hazardous materials release. These actions include the following:

- evacuation,

- sheltering,

- decontamination of people,

- ad hoc respiratory protection,

- control of access,

- shielding,

- control of foodstuffs and water,

- relocation,

- decontamination of land and equipment, and

- medical care.

Offsite Protective Action Recommendations (PARs). PARs will be made to state and local jurisdictions relative to protecting the public from a hazardous materials release. Protecting the public threatened by a hazardous material emergency can be a complicated activity because there is a tremendous range in the circumstances that can be present during an accident.

- The products involved may be extremely hazardous or only temporarily irritating. They may be in pure form or in complex mixtures.

- The way an accidental release of materials occurs - such as during a fire, quickly and suddenly, or over a long period of time - can influence the extent of the danger to the surrounding public.

- Environmental conditions, such as weather and terrain, can have a substantial influence on the speed and extent of the spread of hazardous materials or their effects.

- The public's wide range of potential responses to the emergency may help or hinder officials' efforts to protect them. 
Fig. 3. On-site protective action logic (figure 3 follows this page) 


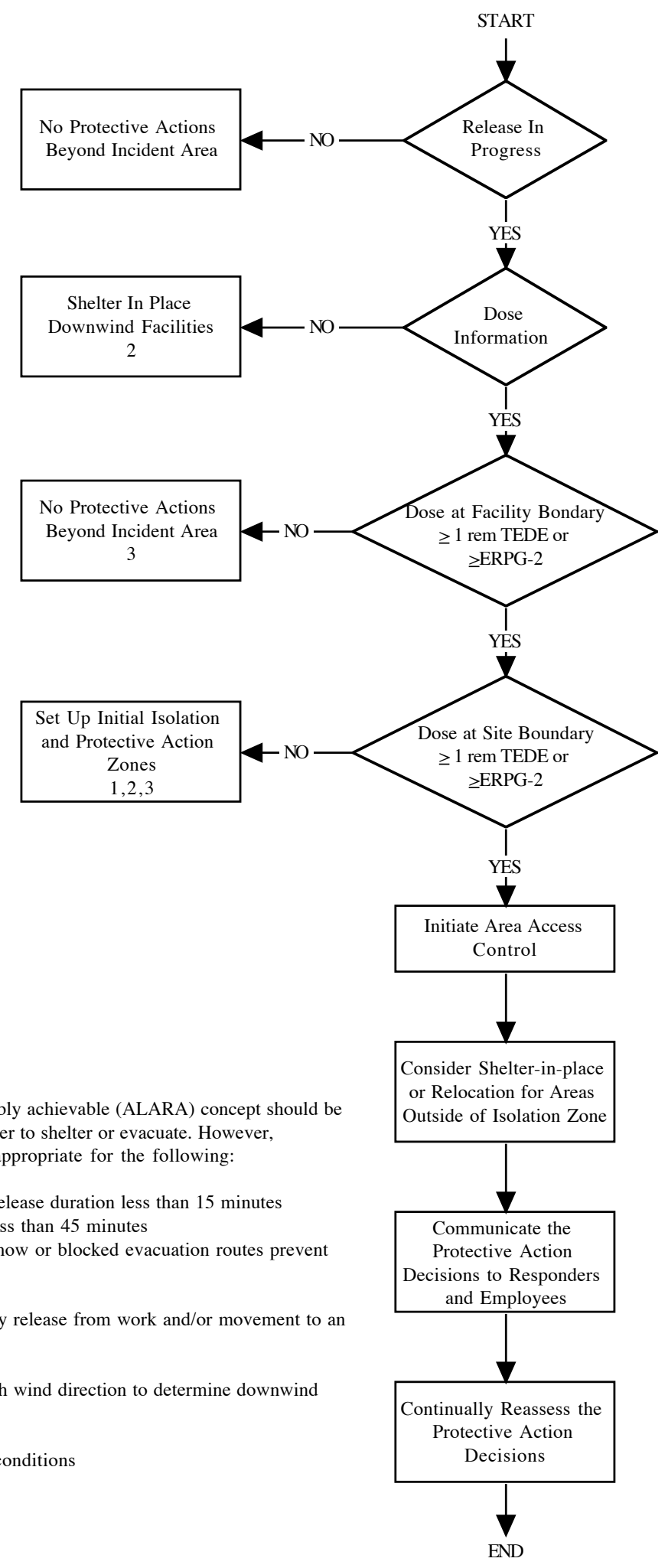


Fig. 4. Off-site protection action recommendation guide (figure 4 follows this page) 


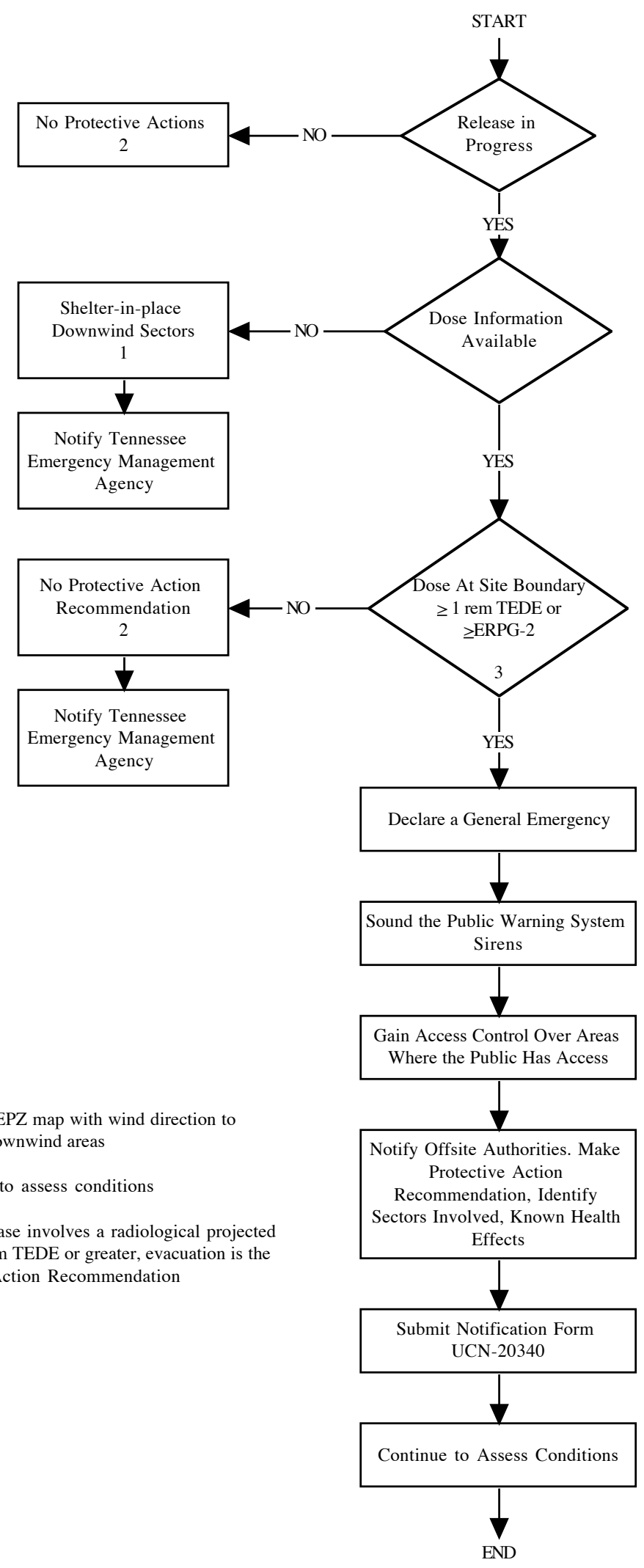

1 Correlate EPZ map with wind direction to determine downwind areas

$\underline{\mathbf{2}}$ Continue to assess conditions

$\underline{3}$ If the release involves a radiological projected dose of 1 rem TEDE or greater, evacuation is the Protective Action Recommendation 


\subsection{TESTING EALs FOR COMPLETENESS}

Test the proposed facility EALs against a range of initiating conditions and accident scenarios to determine if the indicated emergency class is appropriate. Modify or develop additional EALs to ensure prompt classification of the full range of possible emergency conditions.

To compensate for unforeseen conditions, add criterion to declare the level of emergency that most closely corresponds to the apparent conditions, regardless of whether it can be determined that a specific EAL has been exceeded.

\subsection{TRAINING AND IMPLEMENTATION OF EALs}

Facility personnel and applicable plant protection personnel (e.g., PSS, Crisis Manager) are trained on new or revised EALs prior to their implementation. Specifically, training is provided as follows:

1. Designated personnel assigned to the facility receive an overview of the concept of operations contained in EALs and the classification matrixes.

2. All personnel assigned to the ERO, with protective action responsibilities, receive training on EALs. Facility technical management personnel should be familiar with the contents and use of the EMHA.

\subsection{EAL CONFIGURATION MANAGEMENT}

\subsubsection{Review Frequency}

Ensure that EALs are reviewed and assessed whenever significant modifications to the facility process or material inventory occur as part of the EMHA process maintenance.

\subsubsection{Change Control}

The change control process used to ensure that EALs are maintained as up-to-date tools is derived from the process defined in EMPO-558, Oak Ridge Y-12 Plant Emergency Management Hazards Assessment Process. This process is fully based on Y-12-187, "Integrated Safety and Change Control Process."

Relative to the EMHA process, the following change control criteria will initiate a review if a positive screen occurs.

\section{Change Control Criteria}

1. Does the proposed change increase the maximum anticipated quantity of material defined in the approved Hazards Identification (Form UCN-20790)? Include, as applicable, both physical limits (e.g., tank capacity) and associated administrative limits (e.g., maintain tank level $>75 \%$ ). Expected or historical quantities may have been used where physical and administrative limits did not exist.

2. Does the proposed change alter the identified hazardous materials storage and/or process location(s)?

3. Does the proposed change alter the conditions under which material is stored or used? Include process systems or containers that hold the material and barriers/mitigative features that may affect its release or 
dispersion (e.g., shipping containers, buildings, berms sumps, or catch basins). Identify, where applicable, security and access controls for the storage and use locations.

4. Does the proposed change alter the engineered controls, safeguards, or safety systems designed to prevent or mitigate a hazardous materials release? This includes both automatic and manually activated mitigating systems (e.g., fire sprinklers, filters, scrubbers, isolation dampers) as well as passive mitigating features and engineered geometry or configuration controls for fissionable materials.

5. Does the proposed change alter the administrative controls that would prevent or mitigate the initiation of a hazardous materials release? This includes such things as limits on the total quantity of a material in a single place or container, or restrictions on where certain materials can be used or stored.

\subsubsection{Review and Approval of the Facility-Specific EALs}

The facility-specific EALs undergo an internal review by the EMHA team and selected cognizant personnel within the facility prior to being routed for formal review and approval.

As applicable, EALs are reviewed by the following personnel or organizations:

- Facility/Operations Manager

- Subject-Matter Expert(s)

- Y-12 PSS

- $\mathrm{Y}-12 \mathrm{EMPO}$

Allow four to six weeks (maximum) for this review cycle. Comments received after the review cycle should not delay the approval of the document but rather be incorporated into the next revision.

EMPO coordinates the comment review cycle, responds to all comments, and dispositions comments as appropriate.

Upon completion of the review cycle, EALs are approved by the following personnel or organizations:

- Facility/Operations Manager or Event Contractor

- Y-12 PSS

- Y-12 EMPO

\subsubsection{Review and Approval of the Discretionary and Site-Wide EALs}

The discretionary and site-wide EALs undergo an internal review by the EMHA team and selected cognizant subject matter experts prior to being routed for formal review and approval.

As applicable, EALs are reviewed by the following personnel or organizations:

- Subject-Matter Expert(s)

- Y-12 PSS

- $\mathrm{Y}-12 \mathrm{EMPO}$

Allow four to six weeks (maximum) for this review cycle. Comments received after the review cycle should not delay the approval of the document but rather be incorporated into the next revision. 
EMPO coordinates the comment review cycle, responds to all comments, and dispositions comments as appropriate.

Upon completion of the review cycle, EALs are approved by the Y-12 PSS and Y-12 EMPO.

\subsubsection{Revision Control}

Approved EALs are reviewed and revised when any change in the facility or its operations results in an unreviewed safety question. EALs are also reviewed and revised on an annual basis. The annual review allows for $\mathrm{a} \pm 25 \%$ window in its performance and will typically coincide with the EMHA review cycle.

\section{REFERENCES}

- DOE G 151.1-1, Volume III, “Categorization and Classification of Operational Emergencies,” 08/21/97.

- DOE ORDER 151.1, “Comprehensive Emergency Management System,” 09/25/95.

- U.S. EPA 400-R-92-001, Manual of Protective Action Guides and Protective Actions for Nuclear Incidents, May 1992.

- The United States Department of Energy Oak Ridge Reservation Emergency Plan, April 1998, EMPO500 .

- Y-12 Emergency Management Hazards Assessment (EMHA) Process, July 1999, EMPO-558.

- U.S. Department of Health and Human Services, NIOSH Pocket Guide to Chemical Hazards, June 1990.

- The DOT 1996 North American Emergency Response Guidebook (NAERG96). DOT RSPA P 5800.7. Department of Transportation Research and Special Programs Administration. 1996.

- Criteria for Preparation and Evaluation of Radiological Emergency Response Plans and Preparedness in Support of Nuclear Power Plants, NUREG-0654/FEMA-REP-1, Rev. 1. Nuclear Regulatory Commission and Federal Emergency Management Agency. November 1980.

- Methodology for Development of Emergency Action Levels. NUMARC NESP-007, Rev. 1 The Nuclear Management and Resource Council, Inc. February 1991.

- The AIHA 1999 Emergency Response Planning Guidelines and Workplace Environmental Exposure Level Guides Handbook. American Industrial Hygiene Association. 1999. 


\section{APPENDIX A \\ Terms and Definitions}

Alert. Represents events in progress or having occurred that involve an actual or potential substantial reduction in the level of facility safety and protection. On Oak Ridge Reservation, an Alert has occurred if unplanned events result in hazardous material being released to the environment in concentrations that will result in exposures greater than the protective action criteria (PAC) at $30 \mathrm{~m}$ from the source.

Committed Dose Equivalent (CDE). The dose equivalent calculated to be received by a tissue or organ over a 50-year period after the intake of a radionuclide into the body. It does not include contributions from radiation sources external to the body. CDE is expressed in units of rem.

Committed Effective Dose Equivalent (CEDE). The sum of the committed dose equivalents to various tissues or organs over a 50-year period after the intake of a radionuclide into the body. It does not include contributions from radiation sources external to the body. CEDE is expressed in rem.

Consequence. The result or effect (especially projected exposure to radiological or chemical hazards) of a release of hazardous materials to the environment.

Deep Dose Equivalent (DDE). The dose equivalent derived from external radiation at a tissue depth of $1 \mathrm{~cm}$ in tissue. DDE is expressed in rem.

Emergency Action Level (EAL). Specific, predetermined, observable criteria used to detect and recognize, classify, and/or identify the potential of a specific Operational Emergency class.

Emergency class. Differentiates an emergency by the degree of severity, depending on the actual or potential consequence of the emergency. The Operational Emergency subcategory classes are Alert, Site Area Emergency, and General Emergency.

Emergency Management Hazards Assessment (EMHA). Identifies hazards significant enough to include in an emergency preparedness program and forms the technical basis for applicable emergency classification procedures.

Emergency Response Planning Guideline (ERPG). A hazardous chemical material personnel exposure level developed for the general public. A committee of the American Industrial Hygiene Association approves ERPGs.

Facility boundary. Facility boundaries are determined per the Hazards Assessment process. This boundary represents the receptor location used to differentiate between an Alert and a Site Area Emergency declaration.

General Emergency (GE). Represents events that are in progress or have occurred that involve actual or imminent catastrophic failure of facility safety systems with potential for loss of confinement integrity, catastrophic degradation of facility protection systems, or catastrophic failure in safety or protection systems threatening the integrity of a weapon or test device that could lead to substantial off-site impacts. Environmental releases of hazardous materials can reasonably be expected to exceed the appropriate protective action criteria at the site boundary. 


\section{APPENDIX A (continued)}

Hazardous material. Any solid, liquid, or gaseous material that is toxic, flammable, radioactive, corrosive, chemically reactive, or unstable upon prolonged storage in quantities that could pose a threat to life, property, or the environment.

Incipient Stage. Refers to the severity of a fire where the progression is in the early stage and has not developed beyond that which can be extinguished using portable fire extinguishers or handlines flowing up to $125 \mathrm{gpm}(473 \mathrm{~L} / \mathrm{min})$. A fire is considered to be beyond the incipient stage when the use of thermal protective clothing or self-contained breathing apparatus is required or an industrial fire brigade member is required to crawl on the ground or floor to stay below smoke and heat.

Isodose concept. A system of classifying operational emergencies where the consequence threshold remains constant and the receptor location changes ( $30 \mathrm{~m}$, facility boundary, site boundary) to determine emergency classification.

Operational Emergency. Operational emergencies are significant accidents, incidents, events, or natural phenomena which seriously degrade the safety or security of a facility that require time-urgent response from outside the facility. Operational emergencies apply to facilities (nuclear and non-nuclear) involved with hazardous materials; nuclear weapons, components, or test devices; safeguards and security events; and on-site transportation accidents involving hazardous material.

Protective action. Physical measures, such as evacuation or sheltering, taken to prevent potential health hazards (resulting from a release of hazardous materials to the environment) from adversely affecting employees or the off-site population.

Protective Action Criteria (PAC). A personnel radiation exposure level (1 rem) or toxic chemical concentration (ERPG-2) above which protective action is considered.

Release. Normally, an airborne effluent release to the environment as this pathway typically represents the most time-urgent situation. Releases to aquatic and ground pathways in most instances do not have the same time urgency.

Site Area Emergency (SAE). Represents events that are in progress or have occurred involving actual or likely major failure(s) of facility safety or safeguard systems needed for the protection of on-site personnel, the public health and safety, the environment, or national security. Environmental releases of hazardous materials are expected to exceed the appropriate protective action criteria at or beyond the facility boundary but not expected to exceed the appropriate protective action criteria at or beyond the site boundary.

Site boundary. In general, the perimeter of the DOE-owned and controlled land at a site on the Oak Ridge Reservation. The Hazards Assessment determines the closest site boundary for a facility to be used for Emergency Action Level development.

Subject-Matter Expert (SME). Individual considered to be an authority on a particular subject.

Total Effective Dose Equivalent (TEDE). The sum of the deep dose equivalent (for external exposures) and the committed effective dose equivalent (for internal exposures). 
Working Structural Fire. Any structural fire beyond incipient stage is considered to be a working structural fire. 
APPENDIX B

Isodose Concept Table

\begin{tabular}{lll}
\hline \multicolumn{1}{c}{ CLASS } & \multicolumn{1}{c}{ ISODOSE } & \multicolumn{1}{c}{ WHERE } \\
\hline $\begin{array}{l}\text { Alert } \\
>\text { ERPG-2 or equivalent }\end{array}$ & $>1$ rem TEDE & At $30 \mathrm{~m}$ to facility boundary \\
SAE & $>1$ rem TEDE & $\begin{array}{l}\text { Beyond facility boundary to site } \\
\text { boundary }\end{array}$ \\
& $>$ ERPG-2 or equivalent & \\
GE & $>1$ rem TEDE & Beyond the site boundary \\
\hline
\end{tabular}

NOTE:

ERPG Emergency Response Planning Guideline

GE General Emergency

SAE Site Area Emergency

TEDE Total Effective Dose Equivalent 


\section{APPENDIX C \\ Barrier Approach to Emergency Action Level Development}

Introduction

\section{Background}

Barrier Definition
This appendix describes a method for using the condition or state of protective "barriers" as a quantitative measure of facility or process safety degradation for purposes of determining event class.

Operational emergencies involving or affecting Department of Energy (DOE) facilities on the Oak Ridge Reservation (ORR) are placed in one of four classes by degree of severity. The assigned emergency class reflects the actual or potential consequences of the situation. Emergency class definitions are stated in terms of "safety degradation" and "actual or potential failure of safety functions," as well as in units of consequence (dose, exposure, or concentration).

Facilities develop systems and procedures to allow a graded emergency response by viewing physical and administrative controls as the barriers that maintain hazardous material in a safe condition. Construct the Emergency Action Level (EAL) scheme around the status of those barriers.

The EAL schemes developed are either event-based (subjective) or symptom-based (objective) in nature. The character of the specific EAL scheme is largely dependent on the type and level of sophistication of installed systems that monitor the barrier(s) status. The more quantitative the information provided by monitoring systems is, the more symptom-based the EAL scheme can be. Conversely, if monitoring is largely dependent on staff observation of events, the scheme will tend to be more event-based, or subjective.

Facility design features that contain hazardous materials or separate them from people or the environment are physical barriers in the traditional sense. This concept of barriers is the one typically applied when analyzing radiological facilities. In order to develop a complete EAL scheme, consider barriers other than those of a physical nature (such as administrative or procedural controls). Examples of various types of barriers are as follows:

\section{Physical}

- Containment

- Glove Boxes

- Binding Agents

- Confinements

- Hot Cells

- Overpacks

- Cylinders

- Process Piping

- Shipping Casks

- Tanks

- Tunnels/Shafts 


\section{APPENDIX C (continued)}

\section{Configuration}

- Safe Geometry

- Segregated Storage

- Process Controls

- Temperature Controls

- Cryogenic Traps

- Humidity Controls

- Arming Circuits

- Security Systems (e.g., Cipher Locks)

\section{Administrative}

- Inventory Control

- Two-Man Rules

- Access Controls

- Safeguards and Security Rules

Examples of possible barriers by facility function are displayed next.

\begin{tabular}{|l|l|}
\hline \multicolumn{1}{|c|}{ Facility type } & \multicolumn{1}{c|}{ Possible barriers } \\
\hline $\begin{array}{l}\text { Expended fuel } \\
\text { chemical/materials }\end{array}$ & Fuel cladding, storage building, and HVAC system. \\
\hline Processes & Tanks, pipes, traps, hot cells, and building. \\
\hline Rad waste & $\begin{array}{l}\text { Bindings or solidifying agent, drums and tanks, } \\
\text { buildings, geologic containment. }\end{array}$ \\
\hline Toxic material storage & Tanks, cylinders, and building. \\
\hline Weapons and fissile & $\begin{array}{l}\text { Configuration, arming features, assembly facilities, } \\
\text { geologic material containment, configuration controls. }\end{array}$ \\
\hline
\end{tabular}

\section{Criteria for Failure and Challenge of Barriers}

Failure of a barrier can usually be recognized by readings or output from plant instruments such as valve position indicators, failed fuel monitors, pressure sensors, or stack effluent monitors. State the criteria for declaring a particular barrier failed in terms of specific values on specific instruments (e.g., "Main Stack XXX indicates >1.5E8 $\mu \mathrm{Ci} / \mathrm{s}$," or "Any Valve Position Indicator on panel XXX indicates Open").

Consider the barrier failed until conditions are verified otherwise by other means (e.g., visual inspection, portable monitoring equipment, etc.) to achieve an anticipatory and conservative declaration where all indications of a barrier's condition are lost during an upset condition or operating transient. For example: following a building isolation signal, the control room position indicators for two of the ten installed isolation valves/dampers show neither an open nor shut indication. Consider the associated valves/dampers failed open until verified shut by another method.

Consider a barrier Threatened or Challenged if the events in progress may result in a barrier failure. 


\section{APPENDIX C (continued)}

Do not delay classification determination on the expectation that mitigating activities in progress may correct the degraded conditions.

The Emergency Action Level (EAL) statements can take into account the likelihood that corrective actions can and will be taken within the time necessary to prevent barrier failure such that the decision is not left to user. For example, recognition of a fire that could challenge a barrier may be a good basis for classifying the event at a level corresponding to failure of that barrier. If the degree of challenge is directly related to the duration of the fire (and hence to the success of mitigation efforts) and can be reflected in an EAL statement such as "Fire in Zone 1 lasting more than $15 \mathrm{~min}$," where the $15 \mathrm{~min}$ is related to the time that the barrier could remain intact under fire conditions.

\section{EALs Based on Barrier Status}

The method of developing facility-specific EALs based on barrier status is outlined in the following steps:

A. Identify from the facility Hazards Assessment the hazardous materials of significant operational concern.

B. Determine the highest possible potential emergency class for each material, from release of that material, as analyzed in the facility Hazards Assessment.

C. Determine the physical, administrative, and configuration barriers between each of the sources and the outside environment.

D. It is unlikely that more than three levels of barriers (physical and other) can be reasonably credited for any hazard source. Consider no more than three overlying and independent barriers.

NOTE: Do not interpret this to mean that development of EALs for hazardous materials with more than three barriers is not required, but rather that credit is given to a maximum of three barriers, with the remainder being ignored.

The Hazards Assessment provides justification for selecting barriers. For example, a building and its heating, ventilating, air conditioning (HVAC) system are not considered a barrier unless the HVAC filtration system can remove a high enough percentage of the material of interest during the maximum credible release to prevent exceeding any protective action criteria, while maintaining a negative pressure in the building.

NOTE: This method is founded on the assumption that the barriers are approximately equal in their safety significance. If the barriers differ widely in the degree to which they assure control over the hazardous material, their failures (or challenges) cannot be treated as equal safety decrements for purposes of assigning an emergency class. 


\section{APPENDIX C (continued)}

E. Develop facility-specific EALs for each hazardous material using the concepts of barriers "failed" or "challenged" as follows:

1. Select the independent barriers (between the source and the environment) for which credit will be taken.

2. Identify the symptoms or observable indications of the barrier being either failed or challenged for each barrier selected.

3. If all the barriers are either failed or challenged, then the symptoms of their challenge or failure, taken collectively, constitute an EAL for declaring the highest emergency class, identified in step B above.

For example, in the case of a hazardous material source that is capable of producing a General Emergency (GE) and has three barriers preventing its release, the comprehensive EAL set for the GE class would include indications of the following combinations:

- barriers failed

- $\quad$ barriers failed, 1 barrier challenged

- $\quad$ barrier failed, 2 barriers challenged

- 3 barriers challenged

4. For the second and third combinations, there may be three permutations each. For example, if A, $\mathrm{B}$, and $\mathrm{C}$ designate the individual barriers, the second combination (two barriers failed and one challenged), may be either:

- $\quad \mathrm{A}$ and $\mathrm{B}$ failed, $\mathrm{C}$ challenged, or

- $\quad$ A and $C$ failed, B challenged, or

- $\quad$ B and $\mathrm{C}$ failed, A challenged.

5. If all except one barrier is failed or challenged, classify the condition at one level lower than if all are failed or challenged. In the example cited in (3) above, the class would be SAE and the comprehensive EAL set for the SAE class would include indications of the following combinations:

- 2 barriers failed, 1 barrier intact and not challenged;

- 1 barrier failed, 1 barrier challenged, 1 barrier intact and not challenged; and

- 2 barriers challenged, 1 barrier intact and not challenged.

- If all except two barriers are failed or challenged, classify the conditions two levels lower than if all are failed or challenged. For the three-barrier example cited earlier, the class would be ALERT and EALs for the ALERT Classification would be based on indications of one barrier either failed or challenged and two barriers intact and not challenged. This case requires some special attention because the purposeful and controlled breaching of a barrier (in a multiple barrier facility), such as the temporary opening of a truck bay door or the performance of carefully planned maintenance activities on a barrier, should not be considered a failure or challenge. 